\title{
Patrimônio e inventário: a escolha do objeto
}

\author{
Cláudia Regina Plens* \\ Gilberto da Silva Francisco**
}

PLENS, C.R.; FRANCISCO, G.S. Patrimônio e inventário: a escolha do objeto. R. Museu Arq. Etn., 26: 10-26, 2016.

Resumo: Este artigo tem como premissa a discussão de como a sociedade do presente lida com as questões patrimoniais, desde a eleição dos objetos até as consequências das escolhas no saber e gerenciamento do patrimônio. Para tanto, trata os conceitos patrimoniais para depois considerar seus usos, tanto para os tomadores de decisão sobre o patrimônio quanto para a população a quem, de fato, interessa a existência de medidas protetoras de patrimônio. Essa discussão nos dará a base para discutir o modo como a população lida com seus objetos e para a possibilidade de práticas de ações conjuntas com maior justiça e ética entre sociedade civil e órgãos governamentais no que diz respeito ao patrimônio da sociedade.

Palavras-chave: patrimônio; inventário patrimonial; políticas patrimoniais; legislação patrimonial; UNESCO.

“O Poder Público, com a colaboração da comunidade, promoverá e protegerá o patrimônio cultural brasileiro, por meio de inventários, registros, vigilância, tombamento e desapropriação, e de outras formas de acautelamento e preservação" (Constituição Federal de 1988, Art. 216, $\mathrm{V} \S 1$ ).

\section{Introdução}

Em contextos internacionais, há uma latente preocupação com o patrimônio cultural em iminência de risco pelo acelerado desenvolvimento econômico e tecnológico das cidades. Nessa mesma vertente, no Brasil há uma legislação que demonstra a crescente preocupação dos órgãos do Estado com a preservação do patrimônio, cujo montante em investimento em projetos

${ }^{*}$ ) Arqueóloga, Professora do Departamento de História da UNIFESP.

$\left.{ }^{* *}\right)$ Arqueólogo, Professor do Departamento de História da UNIFESP. de Educação Patrimonial se destaca como principal solução articulada por esses órgãos para conservação e manutenção do patrimônio por meio da conscientização do público sobre sua importância (Barreto, 2013: 114).

Contudo, as políticas oficiais de patrimônio tendem a inculcar a importância da preservação e da conservação dos bens ignorando os sentidos divergentes do termo para as populações, inclusive de suas "resistências" ou "negligências". Por sua vez, os estudos de recepção estendem o significado do termo de maneira tão ampla, ao considerar as múltiplas visões das populações que a categoria passa a designar tudo e, ao mesmo tempo, nada, resultando em usos e abusos da memória (Todorov, 2000). 
Este artigo trata dos conceitos patrimoniais para depois considerar seus usos, tanto para os tomadores de decisão sobre o patrimônio quanto para a população a quem, de fato, interessa a existência de medidas protetoras de patrimônio. Essa discussão nos dará base para entender as questões ligadas ao patrimônio de Guarulhos, objeto de inventário e análise do PIPAG, para compreensão de como a população lida com seus objetos e para a possibilidade de práticas de ações conjuntas com maior justiça e ética entre sociedade civil e órgãos governamentais no que diz respeito ao patrimônio da sociedade.

\section{O Valor do Objeto}

Patrimônio não possui um conceito fechado e simples (Graham, Ashworth e Tunbridge, 2000; Harvey, 2001; Larkham, 1995; Schouten, 1995; Tunbridge e Ashworth, 1996; Smith, 2006), pois não tem significado em si mesmo, mas é dependente dos valores atribuídos a ele, resultado de um longo processo de seleção que ocorre no presente, sobretudo a partir da comodificação dos processos econômicos e culturais (Harvey, 2001; Silverman e Ruggles, 2007: 34; Smith, 2006).

Nesse sentido, onde o patrimônio é um processo construído, os objetos, sítios, paisagens e lugares passam por um ciclo de vida em que eles são localizados, interpretados, significados (e ressignificados), classificados, apresentados e conservados, até sua sucessiva perda de significado com o passar dos anos (Harvey, 2006).

De acordo com Smith (2006: 2-3), um dado objeto se torna patrimônio a partir da valorização simbólica a qual os indivíduos the atribuem no presente, e cujo significado pode ser transmitido junto do bem material através das gerações. Ambos os conceitos estão intrinsecamente conectados, o material e seu significado. Assim, Smith (2009: 6) chama a atenção para a coerência em se estipular patrimônio material como distinto do patrimônio imaterial, uma vez que o patrimônio material só existe mediante um conjunto de valores sociais atribuído a ele, que são intangiveis.

Se o significado de patrimônio depende dos valores a ele atribuídos, os significados são mutáveis e se modificam com a concepção de mundo da sociedade através do tempo. Por essa razão, patrimônio não é uma coisa, mas um processo no qual o valor lhe é atribuído a partir de seu reconhecimento, por meio de seu estudo, mapeamento, preservação e conservação.

A escolha de um dado objeto como patrimônio ocorre em detrimento de muitos outros objetos. O que preservar, quais histórias serão contadas e recontadas para as gerações futuras depende de escolhas efetuadas a partir de uma rede de negociação onde a sociedade civil, pesquisadores acadêmicos e instituições governamentais estão conectados por um longo processo de engajamento através dos quais diferentes segmentos da sociedade tratam constantemente de suas posições sociais.

Dentro dessa constante negociação, a história de todos deveria ser representada e o papel de seus objetos, seus patrimônios, valorizados. Nesse sentido, os discursos sobre o patrimônio importam e são decisivos, pois a escrita, a fala e o pensamento sobre o patrimônio influenciam na identificação e gerenciamento do patrimônio (Smith e Waterton, 2009: 290).

Smith (2006; 2009: 292) aponta para uma questão crucial do processo de transformar um dado objeto em patrimônio: a escolha do que será considerado patrimônio. A etapa de escolha do objeto depende de uma performance a partir de critérios adotados em listas de inventários, cujos valores são posteriormente difundidos e reforçados em contextos sociais e coletivos, por meio de ações subsequentes de manutenção, conservação, interpretação e visitação.

De modo geral, a literatura patrimonial que tenta definir seu conceito versa constantemente sobre a conexão intrínseca entre o patrimônio e a identidade social, onde o presente pode ser explicado por meio do passado. Contudo, patrimônio não se define apenas acerca de identidade, mas sobre senso de lugar e de pertencimento, pertencimento ao espaço físico, mas também, e principalmente, ao espaço social (Smith, 2009: 293).

Muito embora os temas patrimoniais estejam cada vez mais em voga, o uso do passado para a criação de identidade e pertencimento não surgiu na modernidade, mas durante toda a história da humanidade os aspectos materiais foram uti- 
ciação de identidades e territorialidade entre as populações (Silverman e Ruggles, 2007: 18).

No Brasil, são inúmeros os problemas advindos dessa leitura superficial do patrimônio pelo foco patrimonial europeu, quando o tombamento é a chave central para o reconhecimento e o respeito pelo patrimônio. Exemplo recente ocorreu no município de Guarulhos com o destombamento e destruição da Casa Saraceni. Tombado pelo Conselho de Patrimônio Histórico de Guarulhos em 2000, o casarão que se encontrava em meio ao estacionamento de um e representava um estorvo do ponto de vista econômico, teve o pedido de seu destombamento em 2009 por um vereador, obtendo aprovação pela Câmara de Vereadores. A despeito das múltiplas reivindicações da sociedade civil contrárias ao seu destombamento, no dia 5 de novembro de 2010, o casarão Saraceni foi demolido na calada da noite...

\section{Patrimônio como Direito}

Embora as preocupações a respeito da proteção de bens culturais sejam notórias, na prática, a proteção efetiva dos bens culturais, assim como o envolvimento da sociedade do seu patrimônio, não acontece de maneira concreta, levando ao crescimento dos debates e críticas com o objetivo de tornar a proteção e o envolvimento da população com seu patrimônio mais efetivo e harmonioso.

Nesse sentido, vêm eclodindo discussões acerca dos problemas da dependência de recomendações de órgãos e agências ligados a governos para proteção dos bens culturais entre arqueólogos e outros agentes em todo o globo.

Cientes de que cada cultura tem dignidade e valores que devem ser respeitados e preservados (Logan, 2007: 35), recentemente vem sendo discutido o que alguns autores chamam de ligação intrínseca entre Patrimônio e Direitos Humanos (Silverman e Ruggles 2007), voltando a uma discussão semelhante à que ocorrera em 1970, quando da conferência (1970; Meskel, 2010).

A Declaração Universal de Direitos Humanos, promulgada em 1948, em seu artigo 27, parágrafo primeiro, declara que "toda a pessoa tem o direito de tomar parte livremente na vida cultural da comunidade, de fruir as artes e de participar no progresso científico e nos benefícios que deste resultam", colocando assim que os aspectos culturais de uma sociedade também fazem parte dos direitos humanos (assim como os artigos 22 e 29).

Contudo, a Comissão de Direitos Humanos e o sistema de Direitos Humanos UN têm sido duramente criticados, primeiramente por eles não serem universais em sua aplicação (Santos, 1997) e por enfatizar os direitos civis e políticos em detrimento dos direitos culturais, sociais e econômicos (Silverman e Ruggles, 2007: 4). Os crimes contra o patrimônio, tal qual a destruição de monumentos e a restrição às práticas culturais, leva à desmoralização de indivíduos, impedindo a compreensão intercultural entre as sociedades, afetando as futuras gerações por apagar a memória cultural (Logan, 2007: 39).

Desse modo, Meskel (2010: 842-4) pondera se de fato o patrimônio deve ser privilegiado sobre a imediata necessidade das pessoas locais, seu direito à vida, segurança e liberdade. A partir desse pensamento, a autora teme situações em que os direitos culturais possam ser invocados para justificar, ou pelo menos usados como desculpas, para violações dos direitos humanos. A autora demonstra casos como os do Kruger, na África, onde os direitos patrimoniais são secundários perante seus problemas relacionados à terra, bem-estar, saúde e educação. Mais do que isso, se os Direitos Humanos lutam incessantemente sem sucesso para que os direitos civis sejam minimamente respeitados, qual efeito surtirá a partir do emprego do conceito de Direitos Humanos para a proteção do patrimônio?

Nesse sistema de escolha de patrimônios, embora Direitos Humanos seja tema da atualidade, onde se clama por justiça histórica e acesso à educação para todos, muitas vezes paisagens naturais têm suplantado histórias de pessoas e as urgências sociais do mundo contemporâneo. Mais do que isso, o discurso de patrimônio da UNESCO, inclusive o paisagístico, globalmente adotado, algumas vezes é empregado como ferramenta para legitimação do poder de alguns 
lizados com propósitos identitários e territoriais (Harvey, 2001: 320). Mas foi no século XVIII que alguns valores europeus passaram a ditar o rumo em que os bens seriam valorados como mais importantes, a partir do senso de poder, grandiosidade e estética. Esses aspectos nortearam a escolha dos monumentos que passaram a exercer o papel de testemunho da história e da arte e por meio de comemorações nesses espaços com o caráter de registrar na memória determinados eventos e valores (Choay, 2001).

Contudo, o uso do discurso patrimonial pode ser atribuído ao nacionalismo e à modernidade neoliberal do século XX. Os discursos nacionalistas e raciais naturalizaram o laço entre identidade, história e território (Smith, 2006: 18) e, consequentemente, influenciaram o campo das ciências e também a pesquisa arqueológica no século XX, sobretudo em países de tradições imperialistas e nacionalistas. $\mathrm{O}$ que levou muitas vezes ao enviesamento das interpretações das sociedades humanas do passado em prol de uma agenda da modernidade (Trigger, 1994; Kohl e Fawacett, 1995: 2).

A Arqueologia Imperialista e Nacionalista na Europa que ocorreu no período de guerras mundiais levou à destruição e dilapidação do patrimônio de modo rápido e acelerado, levando a própria sociedade civil a criar grupos preocupados em proteger suas identidades e territórios a partir de sua herança patrimonial.

Nessa confluência de problemas ligados ao patrimônio europeu, em 1972 foi criada, pela Organização das Nações Unidas para a Ciência e a Cultura (UNESCO), a Convenção do Patrimônio Mundial, que teve por finalidade incentivar a preservação de bens culturais e naturais de importância para a humanidade, cabendo aos países signatários dessa Convenção a indicação de bens culturais e naturais a serem submetidos à Lista do Patrimônio Mundial.

Desde então, as informações sobre cada candidatura são avaliadas por comissões técnicas, sendo a aprovação final realizada anualmente pelo Comitê do Patrimônio Mundial. De maneira que, subsequentemente, a UNESCO passou a legislar tanto na escolha quanto nos modos em que o patrimônio deveria ser acessado e manejado.
Dentro desse âmbito, as nações em todo o globo passaram a seguir as normas estipuladas pela UNESCO para a indicação de objetos a serem patrimonializados, bem como para os protocolos de pesquisa e proteção, conservação e turismo de seus próprios bens, sob o jugo europeu.

Durante as primeiras décadas de atuação da UNESCO para incentivo da preservação do patrimônio cultural e natural, geralmente as indicações e reconhecimento do patrimônio foram atribuídas ao material tangivel, de grande porte, monumental, estético, de maior profundidade temporal, de valor universal.

Embora salutar, os objetivos da UNESCO pelas importantes contribuições para o reconhecimento do patrimônio - pela facilitação da comunicação, aprendizado e guia das posturas patrimoniais -, dada a diversidade cultural do globo terrestre, as definições adotadas pela entidade acabaram por restringir o que pode ser reconhecido como patrimônio, bem como a manutenção das práticas culturais a ele ligadas.

Essa restrição aos conceitos de patrimônio, que dita regras de modo generalizado para diferentes culturas, vem trazendo problemas fundamentais intrinsicamente semelhantes. Vários países não conseguiram encaixar suas culturas, seus patrimônios, dentro dos conceitos adotados pela entidade, e se tratando de uma entidade governamental, a UNESCO acaba por valorizar governos nacionais, fazendo com que minorias comunitárias dentro dos Estados-Nações, tanto sob regimes repressivos ou democráticos, tenham o reconhecimento de suas expressões culturais pela soberania nacional negado (Smith, 2009: 5; Silverman e Ruggles, 2007: 3).

Em contrapartida, diferentes nações vêm adotando os conceitos de maneira acrítica e superficial, gerando problemas que evidenciam que, assim como o patrimônio pode unir a sociedade a partir de seu legado de valores ligados à história e aos sentimentos, ele também pode dividir e criar barreiras. Em muitos casos, os conflitos gerados pela disputa pelo reconhecimento da UNESCO do patrimônio cultural fizeram com que as medidas que tiveram por objetivo proteger os direitos da população pela cultura se tornassem ferramentas de opressão entre nego- 
grupos, aumentando tensões em áreas de conflito (Meskel, 2010: 843).

De acordo com Smith (2006), existe o que a autora chama de - Discurso Ocidental Autorizado (tradução livre) -, que legisla sobre o que é patrimônio, em contrapartida às práticas sociais e discursos populares acerca do patrimônio. Esse discurso acaba por enfatizar os conceitos da elite, de formação europeia sobre o patrimônio, que privilegiam os bens de profundidade temporal, estética, monumentalidade e expertise. Todo o discurso é carregado de poder, principalmente os adotados por agências sancionadas pelas nações, como a UNESCO, onde predominam as narrativas nacionais, de classe, cultura e etnicidade.

Neste sentido, Boaventura de Sousa Santos (1997) defende a tese de que enquanto os direitos humanos forem concebidos como globalizados, sobrepondo o jugo ocidental para a proteção dos direitos humanos sobre todas as culturas, a sua abrangência entre as sociedades será relativa por esbarrar em reconceitualizações multiculturais. Dessa maneira, os Direitos Humanos e o direito ao patrimônio têm de ser forjados no próprio âmago cultural de uma sociedade.

Nem a UNESCO e tampouco os Direitos Humanos poderão auxiliar sozinhos as comunidades acerca das questões patrimoniais. É o comprometimento da sociedade civil e dos governos locais em prol do aumento das responsabilidades que poderá transpor as barreiras para a proteção patrimonial (Logan, 2007: 50). A possibilidade de que se consiga chegar a um protocolo único para medidas de escolha até a subsequente proteção do patrimônio que abarque as reais necessidades das comunidades em todo o globo é ínfima e, por essa razão, outras estratégias devem ser traçadas para a preservação da sociedade em seu direito ao seu patrimônio.

(...) premissas de um diálogo intercultural sobre a dignidade humana que pode levar, eventualmente, a uma concepção mestiça de direitos humanos, uma concepção que, em vez de recorrer a falsos universalismos, se organiza como constelação de sentidos locais, mutuamente inteligíveis, e se constitui em redes de referências normativas capacitantes (Santos, 1997).
A Arqueologia que costumeiramente lida com objetos para a análise de seus significados, indiferente de seu reconhecimento por órgãos institucionais, mostra que cada objeto carrega importância histórica e emocional, dando diferentes perspectivas de identidade social, senso de pertencimento de um indivíduo ou da história de grupos dentro de sua comunidade.

Os objetos com significado histórico e emocional são muitos e variados, em diferentes escalas de abrangência, desde o patrimônio de interesse internacional, até aqueles de interesse nacional, estadual, municipal, de grupos sociais, familiares e individuais. A análise dessa amálgama de objetos permite acessar histórias de vida cotidianas de uma sociedade até seu presente, possibilitando a sociedade conjecturar um futuro em que a alta gama de representações sociais esteja presente de maneira menos conflituosa.

\section{O inventário patrimonial}

A reflexão sobre o inventário de patrimônio cultural deve ser feita considerando o debate sobre a caracterização do patrimônio e as partes envolvidas na sua proteção, como a sociedade civil e o estado. No caso do Brasil, a política patrimonial é organizada a partir de uma série de elementos regulatórios, como artigos da Constituição Federal de 1988 (artigo 20, 215 e 216), legislação federal (Leis ns. 3.924/61; 7.542/86 e 10.166/00; Lei n. 9.605/98 e Lei n. 12.527), portarias (IPHAN ns. 07/88; 230/02 e 28/03 e Interministerial n. 419/11) e resoluções (CONAMA 01/86), que acabam orientando as práticas dos profissionais relacionados ao trabalho com o patrimônio desde a sua identificação até processos de patrimonialização e educação patrimonial. ${ }^{1}$ E, nesse conjunto de referências, aparece algo da própria concepção legal sobre o que é patrimônio que, vale lembrar, é bastante variada.

A maior parte desse repertório indicado está ligado às dinâmicas próprias do patrimônio arqueológico, considerando atividades situadas entre ações iniciais como o inventário, até a política de tombamento e gestão desse tipo de 
patrimônio, abordando a caracterização dos sítios arqueológicos como bens da União (Artigo 20 da Constituição Federal de 1988), a legislação específica visando controlar exploração de bens patrimoniais, estabelecendo punições para destruição de bens patrimoniais e definindo sítios arqueológicos de organização específica que devem ter prioridades para pesquisa e regras para os pedidos de pesquisa, como os sítios pré -históricos e subaquáticos ou submersos, bem como as regras de sua exploração (Leis Federais 3.924/61, 7.542/86 e 10.166/00).

Além disso, há portarias do órgão federal responsável pela política patrimonial, o IPHAN (Instituto do Patrimônio Histórico e Artístico Nacional), sobre procedimentos para o licenciamento de pesquisas em sítios arqueológicos, para licenciamento de projetos de salvamento arqueológico e Educação Patrimonial e a Arqueologia de Contrato no âmbito dos empreendimentos hidrelétricos (Portarias IPHAN 07/88, 230/02 e 28/03), ratificadas por outros mecanismos de proteção, como a Portaria Interministerial 419/11 (sobre procedimentos e critérios gerais para a elaboração de Estudo de Impacto Ambiental - EIA e o Relatório de Impacto Ambiental - RIMA, instrumentos do licenciamento ambiental), a Resolução CONAMA (Conselho Nacional do Meio Ambiente) 01/86 sobre os fundamentos de estudo de impacto ambiental em empreendimentos lesivos ao meio ambiente, incluindo os estudos do patrimônio arqueológico e cultural, e a Lei de acesso à informação (n. 12.527, de 18 de novembro de 2011) no qual se estabelece que todo e qualquer relatório científico é de acesso público.

Entretanto, a especificidade do patrimônio arqueológico como área a ser explorada conecta-se frequentemente com outras esferas patrimoniais situadas no campo maior chamado

1 Para a legislação sobre patrimônio cultural, ver ARMELIN, 2008 e MONTICELLI, 2010: 73-123.

2 É importante notar que, mesmo que haja uma interação dinâmica entre o campo do material e do imaterial que escapa às estratégias acadêmicas que os discerne, no campo das políticas de proteção do patrimônio, a distinção é importante, já que o que se convenciona chamar de patrimônio cultural "patrimônio cultural" (fig. 1), o qual também é pensado e discutido na legislação anteriormente citada. Por exemplo, a garantia do pleno exercício dos direitos culturais e acesso às fontes da cultura nacional e a definição de patrimônio cultural como bens de natureza material e imaterial (artigos 215 e 216 da Constituição Federal de 1988), e há legislação sobre crimes contra o patrimônio cultural e suas penalidades (Lei Federal n. 9.605/98). Há, dessa forma, um nível mais amplo de patrimônio, o cultural, no qual nos situaremos nessa pesquisa. Essa opção pode ainda ser mais precisa: interessa, sobretudo, o campo caracterizado como "material”, e não apenas o exclusivamente "arqueológico", opção que foi se desenvolvendo ao longo da pesquisa. Entretanto, a própria distinção entre as esferas do "material" e do "imaterial" no debate sobre o patrimônio cultural é insuficiente, considerando a profunda interação entre elas. Assim, para bem compreender a materialidade, recorremos quando necessário à imaterialidade. $^{2}$

Assim, sob a égide de "patrimônio cultural”, pensa-se em uma distinção entre os campos do "material" ou "imaterial", mas mesmo nesses campos específicos há variedade interna. Por exemplo, quanto à materialidade, fala-se em patrimônio histórico, arqueológico, edificado, paisagístico, móvel, imóvel etc. Ou seja, um elemento importante para a discussão sobre o patrimônio é a caracterização, nem sempre explícita, dos tipos de patrimônio. E essa situação projeta-se ao campo da ação de inventariar: pode-se pensar em inventários de bens específicos, por exemplo, de documentos oficiais, de danças, de construções coloniais e também o inventário de elementos mais complexos como um conjunto urbanístico, uma paisagem, uma cidade; e, nesses casos, como lidar com material e imaterial têm instrumentos diferentes. Se, no caso do patrimônio material, um dos instrumentos mais importantes é o tombamento, para o patrimônio imaterial outros instrumentos como o registro, conforme o Decreto n. 3551 de 4 de agosto de 2000, são mais adequados. Para as questões específicas de gerenciamento do patrimônio cultural imaterial no Brasil, ver MENEZES, 2006 e CAVALCANTI; FONSECA, 2008. 


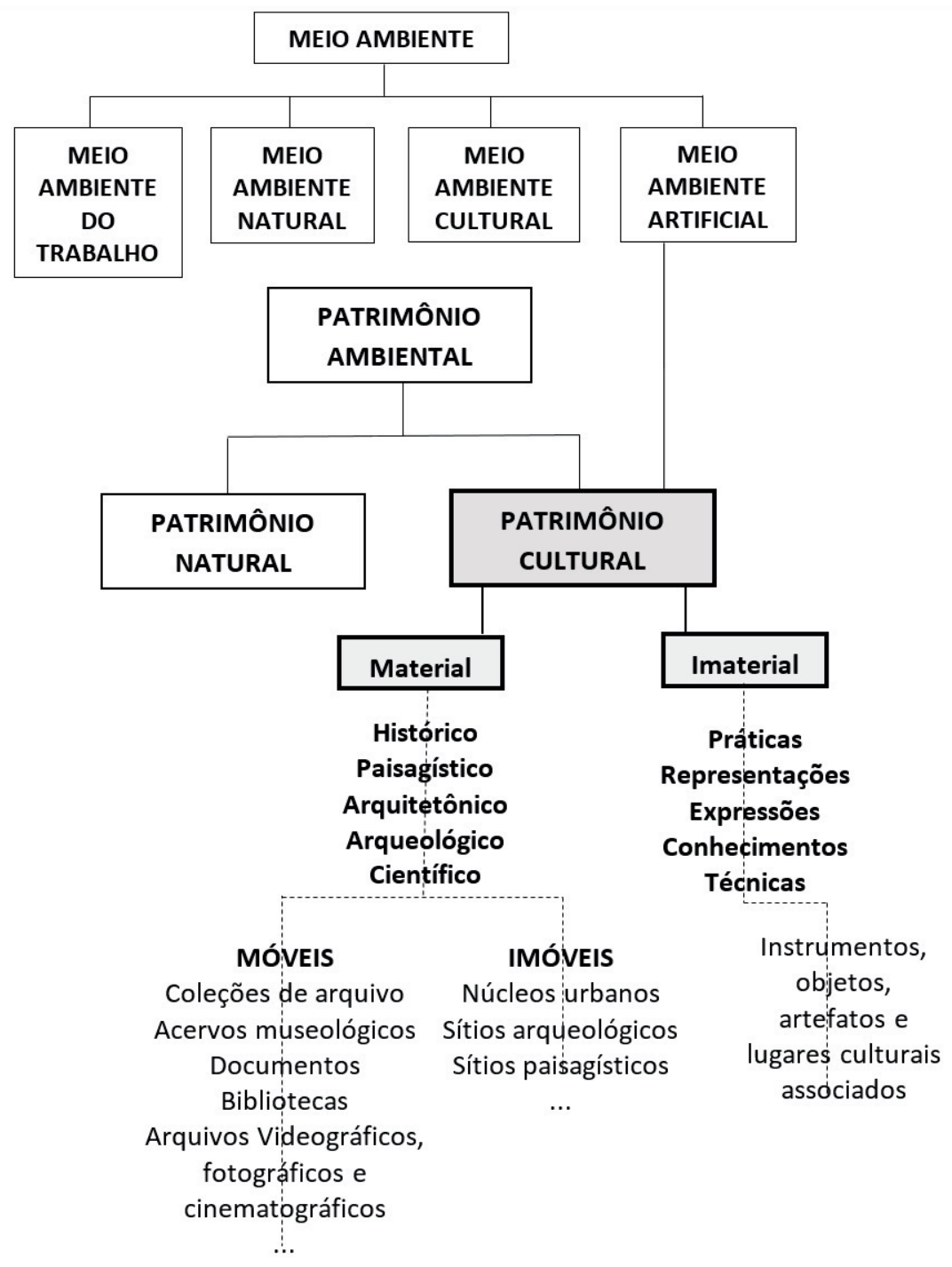

Fig. 1. Diagrama com tipos de patrimônio.

os vários tipos de patrimônios potencialmente incluídos? Em estratégias mais tradicionais, o inventário patrimonial de cidades é o levantamento de monumentos, conjuntos de edifícios ou edifícios isolados, sítios de valor histórico, estético, arqueológico, científico, etnológico e antropológico, respondendo a própria noção da UNESCO (Organização das Nações Unidas para a Educação, a Ciência e a Cultura) quanto ao tema. Entretanto, ao inventariar um edifício isoladamente, em que medida perde-se a sua relação com o local? Não seria interessante pensar nas apropriações socioculturalmente estabelecidas na tarefa de inventariar? No nosso caso, o PIPAG (Projeto de Inventário do Patrimônio Arqueológico de Guarulhos), a constituição claramente diversificada de bens patrimoniais da cidade proporcionou a constituição de uma equipe interdisciplinar atuando em campos diferentes do patrimônio e estabelecendo diálo- 
gos para que a própria noção de complexidade patrimonial seja discutida.

No campo da materialidade, inicialmente, identificamos paisagens, edificações, objetos móveis, relacionados intimamente com o campo do imaterial. Dessa forma, há que se pensar na especificidade dos patrimônios, mas também nas suas relações. E, mais que isso, qual o elemento central de integração. Pensa-se, assim, que o elemento articulador é a cidade de Guarulhos. Entretanto, o recorte puramente espacial não ajuda, na medida em que esses patrimônios estiveram ligados à constituição de um território situado em um longo processo que foi iniciado no século XVI ou mesmo antes, ${ }^{3}$ e se projeta atualmente na cidade contemporânea. Ou seja, o que atualmente chamamos de Guarulhos não responde à mesma territorialidade nesse longo recorte temporal. A atual cidade de Guarulhos é uma referência inicial, mas ela não delimita absolutamente as dinâmicas territoriais quando se pensa no processo que articulou o que atualmente é compreendido como patrimônio.

Considerando esses pontos, há uma variedade de tipos de patrimônios articulados por um elemento que não é necessariamente fixo. É o processo caracterizado pela mudança que interessa para pensar o patrimônio da cidade de Guarulhos. Há espaços como as minas que foram explorados no passado, abandonados e apenas atualmente são observados como patrimônios da cidade. Outros, como fábricas, foram criados e utilizados com fim específico, o que mudou ao longo do tempo, e atualmente sediam atividades de instituições variadas (é o caso do atual centro cultural guarulhense Adamastor). ${ }^{4} \mathrm{E}$, além disso, entram no interes-

3 Pode-se pensar, nesse sentido, desde a presença indígena anterior ao contato relacionada ao extinto grupo macro-Gê Guarulhos ou Maromomi, na instituição da freguesia de Nossa Senhora da Conceição dos Guarulhos no século XVII e no estabelecimento da mineração no local. Ver ANCHIETA; VIOTTI, 1984: 424-5; PREZIA; HOORNAERT, 2000: 48; PREZIA, 2001: 19; PRADO, CAMPOS e DUARTE, 2004: 27 e 36; SILVA, 2009: 123, n. 57).

4 Para o Centro Cultural Adamastor, sediado na antiga Fábrica de Casimiras Adamastor S.A. (de fiação de lã), ver SANTOS, 2006: 149-50; CARDOSO, 2006: 98-9, 101-2 e 112; CABANNES, 2007: 33 e RODRIGUES et al., 2008 (132): 101-2 e 112. se público como bem patrimonial. Esses são apenas exemplos de como o processo interessa bastante e não apenas o patrimônio na sua época de constituição original. Isso, já que falar em patrimonialização é pensar em significados atribuídos às coisas além da sua constituição original; e o interesse imputado a esses elementos ao longo do tempo, relacionado geralmente a comunidades locais, é essencial.

Nesse sentido, é bastante importante pensar na atividade de inventariar, começando pela própria noção de "inventário cultural/ natural", que pode ser visto como um "levantamento sistemático dos bens culturais e naturais" (Assunção, 2003: 64). Essa breve caracterização já nos dá uma importante pista para a compreensão do inventário, sobretudo aquele ligado ao patrimônio cultural: o caráter sistemático do levantamento. É preciso notar que há vários tipos de inventário: o científico, o abreviado, o de proteção etc. (Teles, 1977: 69), e que a tarefa de inventariar passa, necessariamente, pela escolha crítica do tipo de inventário escolhido, que deve dialogar com as questões próprias do complexo a ser inventariado - para inventariar, é preciso "conhecer a cidade, sua dinâmica, as interações entre suas populações e seus espaços" (Gitahy e Lira, 2007: 287). Ou seja, não existe um inventário padrão, mas há algumas diretrizes amplamente seguidas:

O procedimento para a realização de um inventário pode variar de município para município, mas a tendência é que ele atenda a alguns princípios básicos. Primeiramente, define-se uma área de trabalho para inventariar bens. $O$ critério para a determinação da área deve ser o do interesse que aquela região tem para a preservação e para manter as características originais. Definida a área, desenvolve-se uma pesquisa de gabinete que contemple aspectos históricos para o resgate da formação, do desenvolvimento histórico-cultural, socioeconômico e urbanístico do local. Para tanto, é conveniente a consulta ao acervo/ arquivo e às bibliotecas do município para os levantamentos documental, cartográfico e iconográfico, que deverão ser analisados por especialistas (Assunção, op. cit.). 
Pensando-se nesses princípios básicos, é possível estabelecer alguns objetivos: 1) identificação das "diferentes formas de apropriação e produção de sentidos que conformam as diversas configurações do bairro em sua interface com a cidade"; 2) desenvolvimento de "metodologia de inventário em consonância com o lugar da história e as especificidades do [local]"; 3) produção de "banco de dados que fomente as pesquisas históricas e forneça subsídios para as ações preservacionistas e a melhoria da qualidade de vida para toda a comunidade"; 4) elaboração de "diagnóstico que auxilie na constituição dos pressupostos para o exercício da educação patrimonial”; 5) avaliação preliminar "do material histórico pesquisado com a eleição dos focos/lugares referenciais de apropriação social e com o mapeamento histórico das referências culturais tangíveis e intangiveis (permanência e transformações)"; 6) elaboração de "texto analítico sobre o mapeamento preliminar das referências culturais do [local]". ${ }^{5}$

Outra questão importante é a situação do inventário no conjunto de tarefas relacionadas à proteção patrimonial, já que ele é geralmente visto como o ponto inicial no exercício de patrimonialização. No próprio texto da Constituição de 1988 (ver epígrafe), no qual há a apresentação de certa responsabilidade compartilhada entre o poder público e a sociedade civil (na sua dimensão comunitária) no que se refere à proteção do patrimônio cultural, a ação relacionada à proteção que primeiro aparece é o ato de inventariar, o que é amplamente ratificado pela bibliografia. Dessa forma, quando se pensa na proteção patrimonial, o ato de inventariar é geralmente apresentado como a primeira tarefa, ou seja, dela depende, nessa visão, as outras estratégias de proteção do patrimônio: "o inventário é considerado a primeira forma para a identificação e o reconhecimento da importância de bens culturais e naturais realizados por um município, estado ou nação"

5 Esses objetivos, que nos fornecem uma referência inicial, foram elencados no projeto de inventário de bens culturais do bairro Benfica, em Fortaleza, no Ceará (ver NOGUEIRA et al., 2012, s/p). (ver Assunção, ); e considerado, conjuntamente à identificação do patrimônio, como uma "para a preservação do patrimônio cultural de uma comunidade" (Teles, 1977: 69). Assim,

A identificação de bens de interesse cultural e o inventário são etapas prioritárias para a elaboração de uma política de salvaguarda do patrimônio cultural. É necessário conhecer a cidade, sua dinâmica, as interações entre suas populações e seus espaços para poder estabelecer níveis de proteção de conjuntos urbanos mais significativos para o desenvolvimento local e regional. (...) A elaboração de um inventário de bens de interesse cultural se mostra então como um instrumento para o estabelecimento da política de uso e ocupação do solo, definindo áreas de preservação e áreas de renovação urbana. O inventário torna-se, também, um documento importante para avaliar as transformações urbanas, e, no futuro, documento para estudos sobre a história local (Gitahy e Lira, 2007: 287).

A situação do inventário no que se refere às políticas de preservação é, como visto, claramente situada em um campo de destaque. Seria a partir dele que outras atividades importantes nesse sentido seriam desenvolvidas. Entretanto, é preciso bem situar o inventário entre as dinâmicas anteriores e posteriores para entender melhor sua situação de "ponto inicial". Como visto, caracterizado já no texto da Constituição Federal de 1988, as esferas pública e civil são apresentadas como responsáveis pela proteção do patrimônio. $\mathrm{E}$, destacando o papel das comunidades no que se refere à própria definição dos patrimônios de um local, o ponto inicial não seria necessariamente o inventário. O exercício de inventariar, no que se refere ao patrimônio cultural, deve estar sempre atento às dinâmicas sociais, geralmente estabelecidas no âmbito de comunidades, que valoram os elementos que a compõem. Assim, muito do que é inventariado deveria dialogar com os interesses das comunidades sobre o patrimônio. E, nesse sentido, não só o objeto patrimonializado deve ser incluído nos inventários a partir dos interesses comunitários, mas a própria noção de patrimônio 
pode ser alargada e incluir conceitos não acadêmicos sobre patrimônio.

Entretanto, a condução desse processo se dá, em grande parte, ligada a diferentes esferas do poder público, o que é ressaltado pela bibliografia. A tarefa de inventariar, geralmente de grande alcance, requer o apoio do poder público. Por exemplo, em uma proposta de inventário do patrimônio cultural do Rio Grande do Norte, os pesquisadores conclamam os poderes de nível federal, estadual e municipal a apoiarem o projeto (ver Oliveira e Germano, 2003:83); e, em alguns casos, o inventário é apresentado como referência orientadora do plano diretor do município, como no caso do estudo sobre o patrimônio do município de Farroupilha, no Rio Grande do Sul. ${ }^{6}$ Ou seja, entre os interesses das comunidades relacionadas e o apoio e referência para determinadas ações do poder público, o inventário apresenta-se de forma mais dinâmica e não apenas um ponto inicial. Não seria nem mesmo um ponto, mas uma referência que permeia todas as estratégias de preservação e o registro dos interesses das comunidades com um processo. Dessa forma,

O objetivo do inventário é possibilitar uma leitura conjunta dos aspectos urbanos, históricos, arquitetônicos, tipológicos, morfológicos, socioeconômicos e afetivos do sítio como um todo (Silva, 2007: 157).

A ideia de inventário como um dos importantes instrumentos de proteção do patrimônio remonta aos debates sobre o tema na primeira metade do século XX e, em contexto internacional, várias cartas patrimoniais indicam isso. ${ }^{7}$

6 "O Inventário é parte integrante das Diretrizes da Área Cultural do município de Farroupilha que contempla os seguintes programas: Educação Patrimonial, Preservação do Patrimônio Material e Imaterial e Turismo Cultural, tendo como eixo norteador o Plano Diretor Municipal. O objetivo é uma cidade mais humana, identificada com a sua história e projetando o futuro" (SCHNEIDER e GAUER, 2009: 20).

7 Para algumas das importantes cartas patrimoniais internacionais, ver FUNARI e DOMÍNGUEZ, 2005. Para um levantamento completo das cartas internacionais e nacionais, organizado por Isabelle Cury, ver site do IPHAN, seção Publicações/Cartas Patrimoniais.
A “Carta de Atenas”, de 1931, é um dos mais antigos esforços internacionais de reflexão sobre patrimônio. No item VII, c ("Criar uma documentação internacional” na seção "A conservação dos monumentos e a colaboração internacional”) a posição da conferência impele que "cada Estado, ou as instituições criadas ou reconhecidas competentes para esse fim, publiquem um inventário dos monumentos históricos nacionais acompanhado de fotografias e descrições". Nesse sentido, é importante notar que a ideia de inventário conectada às estratégias de proteção e gestão do patrimônio reaparece em várias cartas patrimoniais, revelando que o inventário é um instrumento reconhecidamente importante no âmbito da discussão internacional sobre o patrimônio, o que já era revelado na Carta de Atenas em 1931 e que reaparece constantemente.

Por exemplo, no texto da Conferência Geral da ONU para a Educação, a Ciência e a Cultura, 13a sessão (1964), composto de recomendações para a proteção do patrimônio cultural, no item III, das "Medidas Recomendadas", a primeira delas é a identificação e inventário de bens culturais, privilegiando o âmbito nacional; e no Artigo 4o da Carta de Lausanne (Carta para Gestão e Proteção de Patrimônio Arqueológico, 1990), o inventário de potencial arqueológico é apresentado como "instrumento de trabalho essencial para elaborar estratégias de proteção ao patrimônio arqueológico. Por conseguinte, o inventário deve ser uma obrigação fundamental na proteção e gestão do patrimônio arqueológico".

Considerando os elementos até aqui apresentados, é importante notar certas especificidades ligadas a dimensões variadas do patrimônio como o tipo de propriedade ${ }^{8}$ a característica do patrimônio (ver nota 2 ) e a esfera do estado responsável por sua gestão. Quanto a isso, é importante notar que o patrimônio geralmente é situado entre polos variados: o internacional,

8 Por exemplo, no texto da Conferência geral da ONU para a Educação, a Ciência e a Cultura, 13a sessão (1964), ressalta-se, no caso da tensão entre patrimônio público e propriedade privada, que "um objeto cultural de propriedade privada deveria permanecer como tal mesmo após sua inclusão no inventário nacional. Este inventário não teria caráter restritivo". 
o nacional e o local (regional/municipal). No tocante às medidas de proteção do patrimônio, como visto, a ação do estado é bastante importante, o que aparece explicitamente em algumas das cartas patrimoniais. No Brasil, durante muito tempo privilegiou-se o âmbito nacional, mas com certa intervenção de outras esferas, como no caso do "Compromisso de Brasília", de 1970, firmado em encontro promovido pelo Ministério da Educação e da Cultura (MEC), do qual participaram secretários de estado, governadores e prefeitos, cujo objetivo era complementar "medidas necessárias à defesa do patrimônio histórico e artístico nacional”, ratificando-se a importância da presença estatal na defesa do patrimônio, aliando-se à pesquisa histórica e à elaboração de inventário que seriam realizados pela universidade (César e Stigliano, 2010: 84).

No caso do patrimônio arqueológico de Guarulhos, é possível notar que são as esferas locais (municipal e estadual) que se ocuparam mais consistentemente de estabelecer politicas de gestão patrimonial. No que se refere às instituições estatais relacionadas à proteção do Patrimônio, em Guarulhos, destaca-se principalmente a de nível municipal. Não há nenhum bem desse município na "Lista de Bens Tombados e Processos em Andamento” do IPHAN. ${ }^{9}$ Quanto à esfera estadual, representada pelo CONDEPHAAT, há apenas dois bens da cidade de Guarulhos constantes na lista de bens tombados: a Reserva estadual da Cantareira e Horto florestal, compreendida entre os municípios de Caieira, São Paulo, Mairiporã e Guarulhos e o Complexo Padre Bento, Antigo Sanatório Padre Bento. Há, em curso, o processo de tombamento de edificações relacionadas a uma obra de intervenção no local para o controle de enchentes na bacia do Rio Baquirivuguaçu. Quanto à esfera municipal, a situação é diferente: amparando-se no Decreto Municipal n. 21143/2000 (Lei Orgânica do Município - Ato das Disposições Transitórias, Art. 28), promoveu-se uma série de tombamentos de bens caracterizados como "patrimônio cultural". São eles:

9 http://www.iphan.gov.br/baixaFcdAnexo.do?id=5024 (Acesso em: dez. de 2014).
Antiga Estação de Trem e Antiga Casa do Chefe da Estação (Casa Amarela); Antiga Fábrica da Adamastor; Antigo Paço Municipal de Guarulhos; Bosque Maia;

Casa da Família Saraceni (tombamento revogado pelo Decreto Municipal n. 28.212, de 4 de novembro de 2010);

Cemitério São João Batista; Colégio Capistrano de Abreu; Escola Conselheiro Crispiniano; Escola Estadual Dulce Breves Neves; Igreja Bom Jesus da Cabeça; Igreja Bom Jesus do Macedo; Igreja de Nossa Senhora de Bonsucesso; Igreja Nosso Senhor do Bom Jesus (Capelinha);

Igreja São João Batista dos Morros; Parque da Vizinhança "Vicente Leporace"; Praça Getúlio Vargas;

Prédio Localizado à Rua Sete de Setembro n. 150, Esq. com Rua Felício Marcondes; Sanatório Padre Bento;

Serra da Cantareira Cabuçu ao Bonsucesso; Sítio da Candinha.

No que se refere à ação do poder municipal, em Guarulhos, devem ser destacadas algumas importantes iniciativas: o Decreto Municipal n. 2.1143/2000, antes indicado (determinando, além do tombamento dos bens indicados, termos de proteção, como a impossibilidade de descaracterização do bem sem autorização de conselho competente, levantamento de informações sobre eles e ciência de eventual proprietário particular ou da esfera do governo do estado); a Lei n. 6055, de 30 de dezembro de 2004, do município de Guarulhos, que institui o plano diretor da cidade, e a Lei n. 6.573, de outubro de 2009, que dispõe sobre a criação do Conselho Municipal do Patrimônio Histórico, e estabelece normas para a preservação e proteção do Patrimônio Histórico, Artístico, Ambiental e Cultural do Município de Guarulhos. No que se refere ao plano diretor de Guarulhos (Lei n. 6055, de 30 de dezembro de 2004), há várias menções importantes a questões ligadas ao patrimônio. No título II (Das diretrizes gerais da política urbana), no capítulo I (Da função social da cidade 
e da propriedade), determina-se o "respeito aos patrimônios cultural, histórico e paisagístico", o que é recuperado no capítulo II, destacando-se a importância do ato de "preservar, recuperar e aproveitar adequadamente" esses patrimônios.

Quanto à situação espacial, no Título III (Do zoneamento, uso e ocupação do solo), capítulo II (Do macrozoneamento), os patrimônios são pensados na organização da cidade por regiões, pensando a estratégia de macrozoneamento também no intuito da "preservação do patrimônio natural, histórico, arqueológico e paisagístico"; criando-se seis tipos de zonas especiais (capitulo III) relacionadas a características específicas de atividades no município, entre elas, a gestão patrimonial. As zonas são as seguintes: de interesse social (ZEIS), aeroportuária (ZA), industrial (ZI), de comércio e de serviços (ZCS), de proteção ambiental (ZPA) e de preservação do patrimônio (ZPP), sendo as ZPP compreendidas em "áreas com significativo valor histórico, cultural, artístico, arquitetônico ou paisagístico, destinadas à preservação da memória e identidade do Município" (art. 35).

Por fim, algumas estratégias mais amplas, nas quais poderia ser incluído o importante trabalho de inventário dos bens patrimoniais, são discutidas no Título VIII (Do desenvolvimento social). É importante notar que, aqui, não há menção específica aos inventários, mas uma caracterização generalista de atividades que podem ser pensadas no âmbito da reflexão de questões patrimoniais da identificação à gestão. No capítulo V (Da cultura, do esporte e do lazer), Art. 105, é dito que "o Poder Público Municipal garantirá a preservação, atualização, ampliação e divulgação da documentação e dos acervos que constituem a memória e o patrimônio cultural da Cidade, bem como das paisagens naturais, construções notáveis e sítios arqueológicos”. E, em parágrafo único, que "as ações de que trata o deste artigo serão efetivadas por intermédio do Museu Histórico Municipal e através do Museu da Aeronáutica mediante convênio com outras instituições e empresas privadas".

Pensando nas instituições mais específicas que lidariam com tais questões, em 2009, criou-se oficialmente o CMPHAAPG (Conselho Municipal do Patrimônio Histórico, Arqueológico, Ar- quitetônico e Paisagístico de Guarulhos), através da Lei n. 6.573, que, além da criação do conselho, estabelece uma série de normas para a preservação do patrimônio guarulhense. Já no primeiro capítulo (Do Conselho Municipal do Patrimônio Histórico, Artístico, Ambiental e Cultural do Município de Guarulhos), apresenta-se a criação do conselho, bem como suas funções, níveis de autonomia para atuação e a cessão de técnicos da prefeitura que auxiliassem suas atividades. $\mathrm{Na}$ sequência, o capítulo II trata "Da Composição do Conselho Municipal do Patrimônio Histórico, Artístico, Ambiental e Cultural do Município de Guarulhos", apresentando os conselheiros e as instituições que eles devam pertencer - um corpo consistente de funcionários municipais, como representantes de secretarias, mas também de representantes de instituições ligadas à sociedade civil, como a Associação de Arquitetos, Engenheiros e Agrônomos de Guarulhos. Destacam-se, aqui, os artigos IX e X, indicando que deve haver, na composição do conselho

IX - um representante do corpo docente de cada instituição de ensino universitário em funcionamento na cidade de Guarulhos;

X - um representante dos estudantes de cada instituição de ensino universitário em funcionamento na cidade de Guarulhos, indicados preferencialmente pelo Centro Acadêmico, Diretório Acadêmico ou por reunião promovida pelos estudantes para este fim;

Dessa forma, percebe-se na composição desse conselho relacionado à gestão patrimonial em Guarulhos certa conexão com um debate mais amplo, na medida em que a interação entre a esfera estatal e a sociedade civil é ratificada. Aqui, vimos alguns exemplos da expressa opção por esse diálogo nas questões patrimoniais, como no texto da constituição brasileira (ver epígrafe), no "Compromisso de Brasília", de 1970 (César e Stigliano, 2010: 84), na qual o papel da universidade é realçado. É importante observar que, mesmo sendo possível a qualquer cidadão se envolver em questões patrimoniais como o pedido de tombamento de determinado bem desde a década de 1930, foi a partir 
do final da década de 1970 que um maior engajamento da sociedade civil com relação às políticas patrimoniais pôde ser observado (Mesentier, 2004: 52). Ainda sobre a interação Estado e sociedade civil, pode-se notar certa projeção internacional. Por exemplo, em Beja, uma cidade na região do Alentejo em Portugal, ampliaram-se políticas colaborativas entre Estado e sociedade civil, o que é um elemento central nas recentes abordagens relacionadas ao patrimônio cultural (Falcão, 1999).

Recuperando o texto da Lei n. 6.573, outra informação importante é que, justamente ali, é apresentada uma definição de patrimônio para o município, dialogando, em certa medida, com as atuais caracterizações do patrimônio, incluindo, por exemplo, elementos do universo material e imaterial. No capítulo III, o artigo 9 diz o seguinte:

Constituem o Patrimônio Histórico, Artístico, Ambiental e Cultural do Município de Guarulhos os bens de natureza material e imaterial, tomados individualmente ou em conjunto, relacionados à identidade, à memória, à ação dos grupos formadores da sociedade guarulhense, dentre os quais se incluem: I - as formas de expressão; II - os modos de criar, fazer e viver; III - as criações científicas, artísticas e tecnológicas; IV - as obras, objetos, documentos, edificações e demais espaços destinados às manifestações artístico-culturais; V - os conjuntos urbanos e sítios de valor histórico, arquitetônico, paisagístico, artístico, arqueológico, paleontológico, ecológico e científico, inerentes às reminiscências da formação de nossa história cultural, dotados pela natureza ou agenciados pela indústria humana.

Definidos os membros do conselho a partir de instituições relevantes no município e de apresentar uma definição de patrimônio, o texto da lei continua nos capítulos seguintes apresentando elementos variados relacionados à proteção e preservação, educação patrimonial, potencial turístico, a situação da propriedade privada no âmbito da patrimonialização de certos bens, procedimentos para tombamento e eventual destombamento, livros de tombo (registro de bens culturais), efeitos do tombamento, intervenções no patrimônio e no entorno, incentivo à preservação, penalidades, entre outros. E, observando esse quadro geral, quanto à caracterização do patrimônio, há ainda elementos relevantes. Por exemplo, no capítulo $\mathrm{V}$ (Do tombamento), artigo 23, estipula-se a existência de quatro livros de tombo específicos, nos quais "serão inscritos os bens a que se refere o disposto do art. 9 desta lei" (antes apresentada). Os livros indicam certa compreensão específica de campos do patrimônio que, nessa perspectiva, é dividido entre "Bens Naturais", "Bens Arqueológicos e Antropológicos", "Bens Imóveis de valor histórico..." e "Bens móveis e Integrados de valor histórico...”.

Foram apresentadas, aqui, algumas questões que consideramos importantes para a reflexão sobre o inventário de patrimônio cultural, abordando desde a própria definição de patrimônio cultural, sua variedade e versões, e a importância da compreensão dessa situação para a atividade de inventariar; além disso, a atuação das esferas do Estado, no que se refere à gestão patrimonial e a ação colaborativa com a sociedade civil para o estabelecimento de um debate mais dinâmico sobre as definições de patrimônio e as práticas relacionadas a ele. Esse projeto, nesse sentido, reconhecendo essa situação, apresenta uma proposta de inventário inicial do patrimônio cultural, sobretudo o material, de Guarulhos, constituído a partir de uma série de estudos sobre processos históricos importantes para se pensar o desenvolvimento histórico do município. Assim, assume-se a perspectiva local e o potencial diálogo mais efetivo com a esfera local do Estado. Ainda, assumindo a variedade de itens patrimoniais, houve a reunião de esforços de especialistas de áreas variadas para a criação de estudos específicos que dialogam entre si, objetivando fornecer base sólida para a compreensão do inventário que segue.

Ou seja, a constituição do inventário dialogou com uma série de referências disponíveis em diferentes debates: as cartas patrimoniais (internacionais e nacionais), a legislação 
(federal, estadual e municipal), as propostas das instituições relacionadas à gestão do patrimônio (IPHAN, CONDEPHAAT e CMPHAAPG), e os debates específicos sobre a história de Guarulhos, apresentados por pesquisadores (docentes e discentes) que colaboraram com a reflexão do desenvolvimento histórico de Guarulhos no detalhe e na discussão mais abrangente.

Por fim, vale ressaltar que entendemos que uma estratégia para que as culturas não fiquem reféns desses discursos embebidos por narrativas do poder para preservação de seus patrimônios é que as próprias sociedades se tornem mais críticas e se recriem a partir de ações que atendam suas necessidades específicas. Usando as palavras de Meskel (2010), a solução está na responsabilidade. Responsabilidade de todos os envolvidos nas questões patrimoniais, desde as comunidades até os órgãos que efetuarão as medidas legais para reconhecimento e proteção de alguns patrimônios.

Sheena Iyengar, em seu livro, diz que todas as narrativas tentam organizar as histórias, variando de lugar para lugar, sendo contadas de múltiplas formas. Se as narrativas são distintas e variáveis, em alguns casos as línguas em que são contadas também são, e nossos discursos podem não ser compreendidos por aqueles que falam diferentes línguas. Nesse caso, é necessária a tra- dução. Não se trata de substituição das narrativas, mas tradução como ato criativo, onde se faz conhecer as narrativas existentes aumentando assim nosso repertório para nossas escolhas.

A comunicação é o veículo através do qual podemos conhecer as múltiplas narrativas acerca dos objetos e poderemos configurar algumas histórias. Não se trata de privilegiar discursos, ou pela expertise ou pela fonte que a história está sendo narrada, mas pela comunicação onde todos possam ser ouvidos. A partir de então, aqueles a quem couber o trabalho da escolha dos objetos que se tornarão patrimônio serão beneficiados pela escolha efetuada a partir do conhecimento, de maneira mais justa e harmoniosa.

\section{O que é liberdade? Liberdade é o direito a} escolha: o direito de criar para si mesmo alternativas de escolhas. Sem a possibilidade escolha um homem não é um homem mas um membro, um instrumento, uma coisa. MacLeish (Poeta norte-americano, ganhador do prêmio Pulitzer). ${ }^{10}$ (Tradução livre)

10 "What is freedom? Freedom is the right to choose: the right to create for oneself the alternatives of choice. Without the possibitity of choice a man is not a man but a member, an instrument, a thing". Archibald MacLeish (Poeta norte-americano, ganhador do prêmio Pulitzer).

PLENS, C.R.; FRANCISCO, G.S. Heritage and inventory: choosing the object. R. Museu Arq. Etn., 26: 10-26, 2016.

Abstract: This paper discusses how contemporary society deals with heritage issues. It examines issues ranging from the selection of objects to that choice's impact on the construction of knowledge and heritage management. Therefore, the paper first presents heritage concepts, and then considers the uses of these concepts both by heritage-related decision makers and by the public, who is, in fact, the ultimate concerned about heritage protective measures. This discussion will provide the basis to discuss how the public deals with its objects. Moreover, the debate also provides the possibility of Civil Society-Government Bodies joint actions related to society's heritage with more justice and ethics.

Keywords: heritage; heritage inventory; heritage politics; heritage legislation; UNESCO. 


\section{Referências Bibliográficas}

Anchieta, J. de; Viotti, H.A. (orgs.). 1984. Cartas correspondência ativa e passiva. Obras Completas, vol. 6. São Paulo: Edições Loyola.

Armelin, P.K. 2008. Patrimônio cultural Ė sistema penal. Curitiba: Juruá.

Assunção, P. 2003. O patrimônio. São Paulo: Edições Loyola.

Barreto, C. 2013. Corpo, Comunicação e Conhecimento: Reflexões para a socialização da herança arqueológica na Amazônia. Revista de Arqueologia (Sociedade de Arqueologia Brasileira. Impresso), v. 26: 112-29.

Bellotto, H.L. 2004. Arquivos permanentes: tratamento documental. Rio de Janeiro: Ed. FGV.

Cabannes, Y. 2007. Instrumentos de articulación entre presupuesto participativo y ordenamiento territorial. In: Martínez, J. R. et al. (org.). Algo esta pasando en Europa... Presupuestos participativos. V jornadas intenacionales. Sevilla del 14 al 16 de noviembre de 2007. Madrid: Instituto Universitario IEPALA Rafael Burgaleta: 23-63.

Cardoso, L.D. 2006. A política educacional no município de Guarulhos/SP: gestão 2001-2004: da construção da rede municipal de educação ao projeto político-pedagógico. Dissertação (Mestrado em Educação). Faculdade de Educação. Universidade Estadual de Campinas, 2006.

Cavalcanti, M.L.V. de C.; Fonseca, M.C.L. 2008. Patrimônio imaterial no Brasil. Legislação e políticas estaduais. Brasília: UNES$\mathrm{CO}$, Educarte.

César, P. de A.B.; Stigliano, B.V. 2010. A viabilidade superestrutural do patrimônio: estudo do Museu da Língua Portuguesa. Cultur - Revista de Cultura e Turismo, ano 4, n. 1 , janeiro.
Choay, F. 2001. A alegoria do patrimônio. São Paulo: Estação Liberdade/UNESP.

Declaração Universal dos Direitos Humanos. Adotada e proclamada pela resolução 217 A (III) da Assembleia Geral das Nações Unidas em 10 de dezembro de 1948. Disponível na Biblioteca Virtual de Direitos Humanos da Universidade de São Paulo: www.direitoshumanos.usp.br

Falcão, J.A. 1999. Crônicas do Simpósio Internacional "Proteção dos bens culturais em situação de emergência". In: Azevedo, C.A.M. et al. (1999) Sentimento, religião e política na época moderna. Lisboa: Universidade Católica Portuguesa. Centro de Estudos de História Religiosa, CEHR-U. CP: 379-81.

Funari, P.P.A.; Domínguez, L. (orgs.). 2005. As cartas internacionais sobre o patrimônio. Textos didáticos n. 57, Campinas: Unicamp/ IFCH.

Gitahy, M.L.C.; Lira, J.T.C. De. 2007. Cidade: impasses e perspectivas. São Paulo: Annablume.

Graham, B.; Ashworth, G.J.; Tunbridge, J.E. 2000. A geography of heritage: Power, culture and economy. London: Arnold.

Harvey, D.C. 2001. Heritage pasts and heritage presents: Temporality, meaning and the scope of heritage studies. International Journal of Heritage Studies, Vol. 7, (4): 319-38.

Harvey, D.C. 2006. Landscape as Heritage and Recreational Resource. KAIN, R.J.P. (ed.). Landscapes of South-West England. England's Landscapes's Series, Vol. 3. London: Harper Collins, English Heritage: 207-28.

Iyengar, S. 2012. The Art of Choosing. London: Abbacus. 
Kohl, P.; Fawacett, C. 1995. Nationalism, Politics, and the practice of Archaeology. Cambridge: Cambridge University Press.

Larkham, P.J. 1995. Heritage as planned and conserved. Herbert, D.T. (ed.). Heritage, tourism and society. Mansell Publishing: 85-116.

Logan, W.S. 2007. Closing Pandora's Box: human rights conundrums in cultural heritage protection'. Silverman H.;Ruggles, D.F. (eds.). Cultural Heritage and Human Rights. New York: Springer.

Menezes, R. 2006. Os sambas, as rodas, os bumbas, os meus e os bois. Princípios, ações e resultados da política de salvaguarda do patrimônio cultural imaterial no Brasil, 2003-2010. Brasilia: IPHAN.

Mesentier, L.M. de. 2004. Intervenções em áreas urbanas patrimoniais: dilemas atuais. In: Lima, E.F.W.; Maleque, M.R. (eds.). Cultura, patrimônio e habitação: possibilidades e modelos. Rio de Janeiro: Viveiros de Castro Ed.: 49-59.

Meskel, L. 2010. Human rights and heritage etics. Anthropological Quarterly, 83 (4): 839-60.

Miranfa, M.P. de S. 2012. Tutela constitucional do patrimônio cultural brasileiro: o inventário como um novo instrumento de proteção. In: Rodrigues, J.E.R.; Miranda, M.P. de S. (orgs.). Estudos de direito do patrimônio cultural. Belo Horizonte: Editora Forum.

Monticelli, G. 2010. Deixe estar: patrimônio, arqueologia e licenciamentos ambientais. Porto Alegre: EdPUCRS.

Nogueira, A.G.R. 2005. Por um inventário dos sentidos: Mário de Andrade e a concepção de patrimônio e inventário. São Paulo: Hucitec.

Nogueira, A.G.R. et al. 2012. Benfica em três tempos: patrimônio, inventário e memória local. In: Chuva, M.; Nogueira, A.G.R. (orgs.). Patrimônio cultural. Rio de Janeiro: Mauad X; FAPERJ.

Oliveira, O.A. de; Germano, J.W. 2003. Os caminhos do Rio Grande do Norte. UFRN, Universidade Federal do Rio Grande do Norte.

Prado, A.A.; Campos, A.; Duarte, A.L. 2004. História da cidade de São Paulo, vol. 1. São Paulo: Paz e Terra.

Prezia, B. 2001. Indígenas em São Paulo: ontem e hoje. São Paulo: Paulinas.

Prezia, B.; Hoonaert, E. 2000. Brasil Indígena 500 Anos de resistência. São Paulo: FTD.

Rodrigues, J. et al. 2008. A Universidade Federal de São Paulo aos 75 Anos: ensaios sobre memória e história. São Paulo: Editora Fap-Unifesp.

Santos, B. de S. 1997. Por uma concepção multicultural de direitos humanos. Revista Crítica de Ciências Sociais, 48: 11-32.

Santos, C.J.F. dos. 2006. Identidade urbana e globalização: a formação dos múltiplos territórios em Guarulhos-SP. São Paulo: Annablume.

Santos, R. da C.C. 2011. O Meio Ambiente em Facetas. São Paulo: Baraúna.

Schneider, C.; Gauer, H. 2009. Revelando Farroupilha: inventário do patrimônio cultural material. Farroupilha: Prefeitura Municipal de Farroupilha.

Schouten, F.F.J. Heritage as Historical Reality. HERBERT, D.E. (ed.). 1995. Heritage, Tourism and Society. London: Mansell Publishing: 21-31.

Silva, M.B.R. 2007. Manual de preenchimento: inventário nacional de bens imóveis sítios urbanos tombados: INBI-SU. IPHAN, Instituto do Patrimônio Histórico e Artístico Nacional. 
Silva, M.B.N. da. 2009. História de São Paulo colonial. São Paulo: EdUNESP.

Silverman, H.; Ruggles, D.F. 2007. Cultural Heritage and Human Rights. New York: Springer.

Smith, L. 2006. Uses of Heritage. London: Routledge.

Smith, L.; Waterton, E. 2009. Taking Archaeology out of Heritage. Newcastle upon Tyne. Cambridge: Cambridge Scholars Publishing.
Teles, L.S. 1977. Manual do patrimônio histórico. Universidade de Caxias do Sul.

Todorov, T. 2000. Los abusos de la memoria. Barcelona: Paidós.

Trigger, B. 1994. "Paradigms in Sudan Archaeology". The International Journal of African Historical Studies. Boston: Boston University African Studies Centre, Vol. 27, (2): 323-45.

Tunridge, J.E.; Ashworth, G.J. 1996. Dissonant Heritage: The Management of the Past as a Resource in Conflict. Chichester: Wille. 